RASĀYAN J. Chem.

Vol. 13 | No. 1 |747 - 756| January - March | 2020 ISSN: 0974-1496 | e-ISSN: 0976-0083 | CODEN: RJCABP http://www.rasayanjournal.com http://www.rasayanjournal.co.in

\title{
ZnO INCORPORATED ON NATURAL ZEOLITE FOR PHOTODEGRADATION OF METHYLENE BLUE
}

\author{
N. P. Diantariani ${ }^{1,2}$, I. Kartini ${ }^{2}$, A. Kuncaka ${ }^{2}$, and E. T. Wahyuni ${ }^{2, *}$ \\ ${ }^{1}$ Department of Chemistry, Universitas Udayana, Bali 80362, Indonesia \\ ${ }^{2}$ Department of Chemistry, Universitas Gadjah Mada, Yogyakarta 55281, Indonesia \\ *E-mail: endang_triw@ugm.ac.id
}

\begin{abstract}
Zinc oxide was incorporated into natural zeolite $(\mathrm{ZnO}-\mathrm{NZ})$ by cation exchange followed by co-precipitation and calcination processes. The effect of the amount of $\mathrm{ZnO}$ loaded in the zeolite framework on the properties and photoactivity was studied. The resulted photocatalysts were characterized and were examined their photodegradation efficiency for methylene blue (MB) degradation under ultraviolet light. The results showed that $\mathrm{ZnO}$ was successfully incorporated and well distributed into the zeolite frameworks. The ZnO-NZ photocatalysts showed a higher specific surface area and wider bandgap than the bare $\mathrm{ZnO}$. The photodegradation activity of $\mathrm{ZnO}-\mathrm{NZ}$ for $\mathrm{MB}$ is twice as high as the bare $\mathrm{ZnO}$. Moreover, the photodegradation activity for $\mathrm{MB}$ depends on the amount of $\mathrm{ZnO}$ loaded in the $\mathrm{ZnO}-\mathrm{NZ}$. Optimum MB photodegradation of $83.05 \%$ was obtained by using $\mathrm{ZnO}-\mathrm{NZ}$ having $6.1 \%$ of $\mathrm{ZnO}$ fraction.
\end{abstract}

Keywords: ZnO, Natural Zeolites, Photocatalysts, Photodegradation, Methylene Blue.

(C) RASĀYAN. All rights reserved

\section{INTRODUCTION}

In recent years, increasing use of dyes in industries such as textile, printing, leather, plastic, pulp mill and paper without adequate wastewater treatment methods has caused severe water pollution. ${ }^{1,2}$ The dyes used in industries usually are difficult to degrade naturally due to the complex and stable aromatic structures. ${ }^{2}$ Methylene blue (MB) is an industrial dye that is widely used to dye silk, cotton, and wood. ${ }^{1,3,4} \mathrm{MB}$ is an organic dye that is often used as a model compound for removing dyes and organic contaminants because it can represent the dyes that have stable heterocyclic aromatic structures ${ }^{4}$, and it is also easy to obtain and to analyze and has an economical price. Although MB is not strongly poisonous, it can have some harmful effects on humans and animals. The dye irritates the gastrointestinal tract if ingested and causes methemoglobinemia, cyanosis, convulsions, tachycardia, and dyspnea if inhaled. ${ }^{2,5}$

Several treatment processes such as biodegradation ${ }^{6}$, bioremediation ${ }^{7}$, adsorption ${ }^{8,9}$, and photocatalytic degradation ${ }^{10-12}$ are currently used in methylene blue removal from wastewater. Among these methods, photocatalytic degradation has a high potential to develop further for its rapid degradation rate, mineralization of dyes to green products, and reduction of the toxicity of dyes. ${ }^{13}$

The photocatalytic degradation method uses UV light and photocatalyst semiconductors to degrade textile dyes through the formation of hydroxyl radicals $(\cdot \mathrm{OH})$ which are highly reactive to dyes. ${ }^{14}$ These hydroxyl radicals can degrade textile dyes into small and non-toxic molecules.

Among various photocatalyst semiconductors, $\mathrm{ZnO}$ has been used as effective, easy synthesis, inexpensive (low production cost) and nontoxic photocatalyst for the degradation of a wide range of different pollutants in recent years. ${ }^{14,15} \mathrm{ZnO}$ has high photocatalytic activity as well as $\mathrm{TiO}_{2}$, but it is rarely explored because of its low photostability due to its easy corrosion by light. ${ }^{16,17}$ The low photostability of $\mathrm{ZnO}$ will reduce its photocatalytic activity when it is used under long-term intensive light exposure. Also, $\mathrm{ZnO}$ photocatalyst has poor adsorption ability toward pollutant substances that limited its catalytic efficiency. ${ }^{18}$

To overcome shortcomings problems of $\mathrm{ZnO}$ so that its photocatalytic activity increase, $\mathrm{ZnO}$ has been supported into porous materials such as zeolites. Zeolites are very suitable as a supporting material

Rasayan J. Chem., 13(1), 747-756(2020)

http://dx.doi.org/10.31788/RJC.2020.1315597

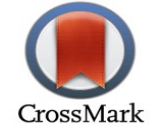




\section{RASĀYAN J. Chem.}

Vol. 13 | No. 1 |747 - 756| January - March | 2020

because they have a high ion-exchange capacity, high surface area, and high adsorption capacity. ${ }^{18}$ Moreover, the zeolite framework preserves $\mathrm{ZnO}$ from photo-decay. ${ }^{18}$ Incorporated $\mathrm{ZnO}$ into zeolites can attract the pollutant substances to the reactive surface of the $\mathrm{ZnO}$ particles where the hydroxyl radicals were produced and also extend the lifetime of $\mathrm{ZnO}$ photocatalyst under light exposure. ${ }^{19}$ The zeolites used by the previous authors were synthetic zeolites that are costly when large amounts are required.

Considering their abundant, cheaper, and eco-friendly, natural zeolites seem preferable than the synthetic ones. In the present work, incorporation of $\mathrm{ZnO}$ into Indonesian natural zeolites for photodegradation of methylene blue is reported. The influence of reaction time, the photocatalyst dose, and MB concentration are also evaluated.

\section{Material}

\section{EXPERIMENTAL}

Zinc acetate dihydrate $\left(\mathrm{ZnC}_{4} \mathrm{H}_{10} \mathrm{O}_{6}\right)$, sodium hydroxide $(\mathrm{NaOH})$, hydrochloric acid $(\mathrm{HCl})$, methylene blue chloride $\left(\mathrm{C}_{16} \mathrm{H}_{18} \mathrm{ClN}_{3} \mathrm{~S}\right)$, and zinc standard solution $1000 \mathrm{mg} / \mathrm{L}$ were purchased from Merck Co. Inc. (Germany). All chemicals were of analytical grade and used without further treatment. The natural zeolite belongs to Klaten Regency, Central Java, Indonesia.

\section{Natural Zeolite Preparation}

The natural zeolite (NZ) was mechanically pretreated, by crushing the granules in a mortar and sieving using a 250 mesh sieve. Then, the NZ powder was immersed in distilled water and heated at $70{ }^{\circ} \mathrm{C}$ for $8 \mathrm{~h}$ under stirring at $500 \mathrm{rpm}$ to remove water-soluble impurities. ${ }^{15}$ After filtration and drying in an oven at $105^{\circ} \mathrm{C}$ for $18 \mathrm{~h}$, the $\mathrm{NZ}$ powder was stored in a desiccator.

\section{Characterization}

The XRD patterns were acquired by X-ray diffractometer (XRD, Philips Analytical) operated at $30 \mathrm{~mA}$ and $40 \mathrm{kV}$ using $\mathrm{Cu} \mathrm{K} \alpha$ radiation $\left(\lambda=1.54060 \AA, 2 \theta\right.$ range 5-80 ${ }^{\circ}$ and 0.02 step size). The FTIR spectra of the samples were recorded on a Fourier transform infrared spectrophotometer (FTIR-PRESTIGE 21) using the $\mathrm{KBr}$ pellet technique in the range of $4000-300 \mathrm{~cm}^{-1}$. The morphological features were recorded by Scanning Electron Microscope which is equipped with Energy Dispersive X-Ray (SEM-EDS, JSM6510LA). UV-Vis diffuse reflectance spectroscopy (UV-Vis DRS) measurements were done using a Shimadzu UV-2450 spectrophotometer. The concentration of zinc in the photocatalysts were determined using flame atomic absorption spectroscopy (FAAS, Analytic Jena ContrAA 300). The specific surface area and pore size of samples were examined using Quantachrome NovaWin $\mathrm{N}_{2}$-Gas Sorption Analyzer (GSA). The degradation extent was monitored by Thermo Scientific Evolution 201 UV-Vis spectrophotometer.

\section{Synthesis of $\mathrm{ZnO}-\mathrm{NZ}$}

The synthesis of $\mathrm{ZnO}-\mathrm{NZ}$ photocatalysts was carried out by the cation exchange method followed by coprecipitation. About 0.7 grams of NZ was dispersed in $50 \mathrm{~mL}$ of zinc acetate dihydrate solution with various concentrations $(0.035 \mathrm{M}, 0.070 \mathrm{M}$ and $0.105 \mathrm{M})$ in $250 \mathrm{~mL}$ round bottom flask. The mixture was refluxed at $80{ }^{\circ} \mathrm{C}$ for $5 \mathrm{~h}$ to allow cations exchange in zeolite cavities with $\mathrm{Zn}$ (II) ions. The solid was separated from the filtrate, then was washed with deionized water and added dropwise with $0.1 \mathrm{M} \mathrm{NaOH}$ solution until the $\mathrm{pH} \cong 12$. The mixture was stirred with a magnetic stirrer for $2 \mathrm{~h}$. The resulted precipitate was washed with deionized water and separated from the liquid by centrifuging at $5000 \mathrm{rpm}$ for 30 minutes. Then it was dried overnight at $\pm 60^{\circ} \mathrm{C}$ and calcined at $400{ }^{\circ} \mathrm{C}$ for $3 \mathrm{~h}$.

\section{Photocatalytic Degradation Experiments}

The photocatalytic degradation of MB in the solution was carried out in a photoreaction reactor equipped with a stirrer and $50 \mathrm{~mL}$ Beaker glasses. The light source used was three Sankyo Denki G20T10 UV-C lamps. For the photocatalytic degradation test, $20 \mathrm{mg}$ of photocatalysts was suspended in $20 \mathrm{~mL}$ of 20 ppm methylene blue (MB) solution in a Beaker glass. The suspension was placed in the photoreaction equipment to be irradiated by UV light accompanied by stirring for various interval times $(15,30,60,90$, 120,150 and 180 minutes). After a given irradiation time, the suspension was centrifuged to remove 


\section{RASĀYAN J. Chem.}

Vol. 13 | No. 1 |747 - 756| January - March | 2020

photocatalyst powder. Afterward, the remains $\mathrm{MB}$ in the filtrate was analyzed by using a Thermo Scientific Evolution $201 \mathrm{UV}$-Vis spectrophotometer at $663 \mathrm{~nm}$ to determine the MB concentration. The percentage of MB degradation (D), was calculated according to Eq. (1):

$$
D \%=\left(\frac{C_{0}-C_{t}}{C_{0}}\right) \times 100
$$

Where, $\mathrm{C}_{0}$ is the initial concentrations of $\mathrm{MB}$ and $\mathrm{Ct}$ is the concentration of $\mathrm{MB}$ at $\mathrm{t}$ time.

\section{Determination of Zn Incorporated Into The Zeolite}

RESULTS AND DISCUSSION

The influences of initial $\mathrm{Zn}$ (II) concentration on $\mathrm{ZnO}$ formed on the zeolite are displayed in Table-1. It is seen in the table that increasing the initial $\mathrm{Zn}$ (II) concentration could increase the $\mathrm{ZnO}$ incorporated on the zeolite. The increase of the $\mathrm{Zn}$ (II) concentration, gave more $\mathrm{Zn}$ (II) ions in the solutions led to an increase in a collision between the ion and the zeolite active surface that can improve the effectiveness of the ion exchange toward cations in the zeolite.

\section{XRD}

The XRD patterns of bare $\mathrm{ZnO}$, natural zeolite (NZ), and $\mathrm{ZnO-NZ} \mathrm{are} \mathrm{presented} \mathrm{in} \mathrm{Fig.-1(a).} \mathrm{In} \mathrm{the} \mathrm{XRD}$ pattern of the bare $\mathrm{ZnO}$, the characteristic peaks at $2 \theta 31.8^{\circ}, 34.4^{\circ}, 36.3^{\circ}, 47.6^{\circ}, 56.6^{\circ}, 62.9^{\circ}, 68.0^{\circ}$, and $69.1^{\circ}$ are observed corresponding to the (lllll $\left.\begin{array}{lll}0 & 0\end{array}\right),\left(\begin{array}{lll}0 & 0 & 2\end{array}\right),\left(\begin{array}{lll}1 & 0 & 1\end{array}\right),\left(\begin{array}{lll}1 & 0 & 2\end{array}\right),\left(\begin{array}{lll}1 & 1 & 0\end{array}\right),\left(\begin{array}{lll}1 & 0 & 3\end{array}\right),\left(\begin{array}{lll}1 & 1 & 2\end{array}\right)$ and $\left(\begin{array}{ll}2 & 0\end{array}\right.$ 1) crystal planes of the $\mathrm{ZnO}$ with hexagonal structure, as documented in JCPDS File 89-0511.

The XRD pattern of natural zeolite (NZ) exhibits peaks at $9.9^{\circ}, 11.2^{\circ}, 17.3^{\circ}, 19.1^{\circ}, 22.4^{\circ}, 26.3^{\circ}$, and $30.0^{\circ}$. These XRD peaks are matched with the corresponding data of clinoptilolite (JCPDS file 25-1349). The peak at $9.9^{\circ}, 11.2^{\circ}, 17.3^{\circ}, 19.1^{\circ}, 22.4^{\circ}, 28.1^{\circ}$, and $30.0^{\circ}$ are matched with the JCPDS file 53-1176 of heulandite. Also, peaks at $2 \theta 9.9^{\circ}, 13.5^{\circ}, 19.6,22.4^{\circ}, 25.6^{\circ}$, and $27.7^{\circ}$ are characteristic of mordenite (JCPDS file 29-1257). It is confirmed that Indonesian natural zeolite as composed of clinoptilolite, heulandite and mordenite zeolite types as major components.

Generally, the diffraction patterns of the natural and modified natural zeolite are similar. The positions of diffraction peaks are almost identical, indicating that $\mathrm{ZnO}$ loading does not change the crystal structure of the zeolite. The XRD patterns of $\mathrm{ZnO}-\mathrm{NZ}$ did not show characteristic peaks of $\mathrm{ZnO}$. These could due to the formation of a very small size $\mathrm{ZnO}$ or the presence of a small quantity of $\mathrm{ZnO}$, typically below $9.0 \% .^{20,21}$

\section{FTIR}

The FTIR spectra of the bare $\mathrm{ZnO}$, natural zeolite, $\mathrm{ZnO}(3.5 \%)-\mathrm{NZ}, \mathrm{ZnO}(5.0 \%)-\mathrm{NZ}$ and $\mathrm{ZnO}(6.1 \%)-\mathrm{NZ}$ in the wavenumber range of $4000-300 \mathrm{~cm}^{-1}$ are presented in Fig.-1(b). In the FTIR spectrum of natural zeolite, it is seen the broad absorption band at $3700-3000 \mathrm{~cm}^{-1}$ corresponding to $\mathrm{O}-\mathrm{H}$ stretching vibration which relates to $\equiv \mathrm{Al}-\mathrm{OH}-\mathrm{Si} \equiv{ }^{15}$, and water molecules that are physically absorbed. ${ }^{22}$ The $\mathrm{O}-\mathrm{H}$ bending vibration of the absorbed water molecule is observed at $1636 \mathrm{~cm}^{-1}{ }^{18,23}$ The characteristic band of zeolite appeared at $1049 \mathrm{~cm}^{-1}$ are assigned to $\mathrm{Si}(\mathrm{Al})-\mathrm{O}$ as asymmetric stretching vibration, whereas the band at $795 \mathrm{~cm}^{-1}$ are assigned to $\mathrm{Si}(\mathrm{Al})-\mathrm{O}$ as symmetric stretching vibration. The band at $471 \mathrm{~cm}^{-1}$, corresponding to $\mathrm{Si}(\mathrm{Al})-\mathrm{O}$ bending vibration. ${ }^{15,24}$ The presence of the absorption peak at $594 \mathrm{~cm}^{-1}$ indicates the double ring of external linkage of zeolite from the heulandite phase. ${ }^{24,25}$ The stretching vibration of $\mathrm{ZnO}$ appears at wavenumber $400-500 \mathrm{~cm}^{-1}$ belonged to the $\mathrm{Zn}-\mathrm{O}$ bond. ${ }^{18}$

Table-1: The Influence of Initial $\mathrm{Zn}(\mathrm{II})$ Concentration on the $\mathrm{ZnO}$ Formed on $\mathrm{ZnO}-\mathrm{NZ}$

\begin{tabular}{c|c|c}
\hline $\begin{array}{c}\text { Initial Zn (II) Concentration } \\
(\mathrm{mole} / \mathrm{L})\end{array}$ & $\begin{array}{c}\text { ZnO incorporated on } \\
\text { Zeolite }(\%)\end{array}$ & The Photocatalyst Code \\
\hline 0.035 & 3.5 & $\mathrm{ZnO}(3.5 \%)-\mathrm{NZ}$ \\
\hline 0.070 & 5.0 & $\mathrm{ZnO}(5.0 \%)-\mathrm{NZ}$ \\
\hline 0.105 & 6.1 & $\mathrm{ZnO}(6.1 \%)-\mathrm{NZ}$ \\
\hline
\end{tabular}


RASĀYAN J. Chem.

Vol. 13 | No. 1 |747-756| January - March | 2020
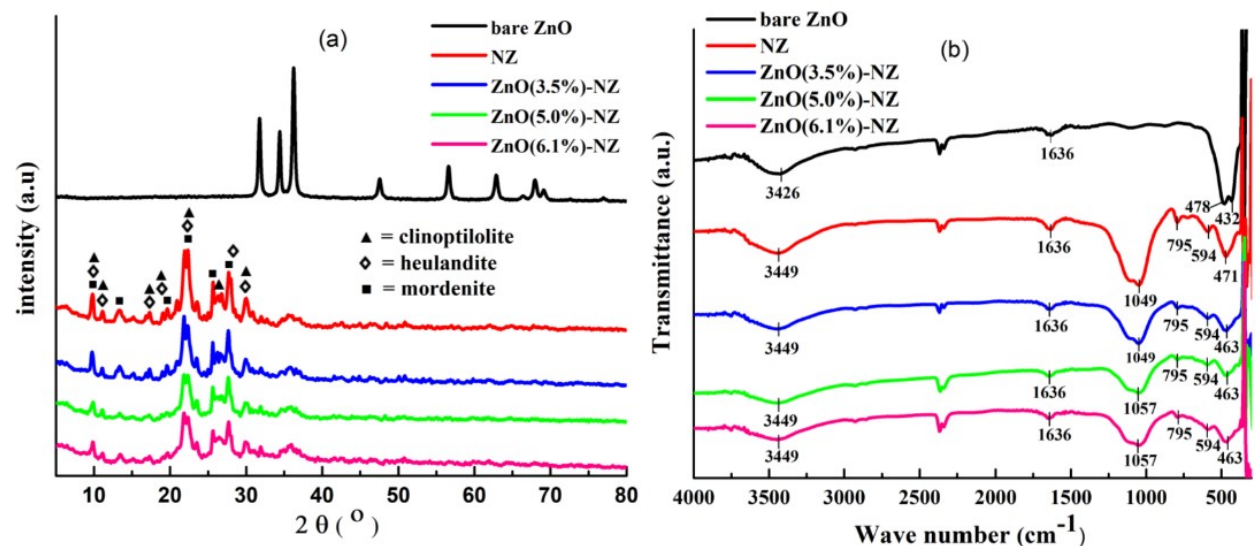

Fig.-1: XRD Pattern (a) and Infrared Spectra (b) of ZnO, NZ, and ZnO-NZ

It is seen that the infrared spectra of $\mathrm{ZnO}-\mathrm{NZ}$ are combination peaks of zeolite and $\mathrm{ZnO}$. The broadening of the band at $400-500 \mathrm{~cm}^{-1}$ is observed, due to the stretching $\mathrm{Zn}-\mathrm{O}$ band along with a vibrational band of the zeolite framework. Also, there is a slight shift in the peak position of $\mathrm{Si}(\mathrm{Al})-\mathrm{O}$ band from $1049 \mathrm{~cm}^{-1}$ to $1057 \mathrm{~cm}^{-1}$ and from $471 \mathrm{~cm}^{-1}$ to $463 \mathrm{~cm}^{-1}$. These wavelength shifts indicate a change in the frequency of vibration of Si-O-Al due to the bonding or strong interaction of $\mathrm{Zn}-\mathrm{O}$ with the zeolites framework.

\section{SEM-EDS}

SEM-EDS is used for determining the morphology of samples and the distribution of elements in the samples. The SEM images of the photocatalysts are given in Fig.-2.

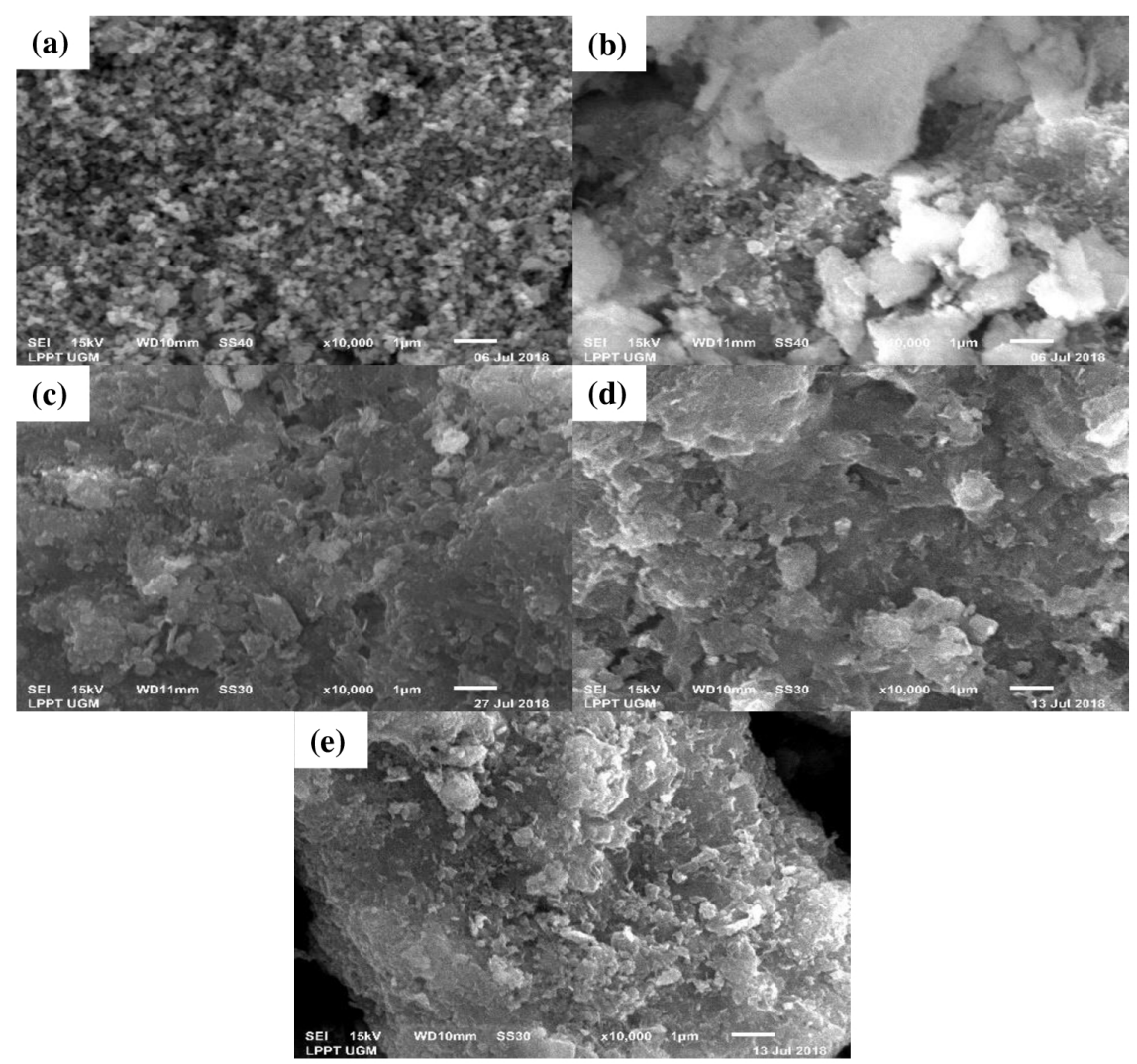

Fig.-2: SEM Images of $\mathrm{ZnO}$ (a), Natural Zeolite (b), $\mathrm{ZnO}(3.5 \%)-\mathrm{NZ}$ (c), $\mathrm{ZnO}(5.0 \%)-\mathrm{NZ}$ (d) and $\mathrm{ZnO}(6.1 \%)-\mathrm{NZ}(\mathrm{e})$ 
RASĀYAN J. Chem.

Vol. 13 | No. 1 |747 - 756| January - March | 2020

The SEM image Fig.-2(a) shows that the bare ZnO has a spherical shape. The SEM image of the natural zeolite (Fig.-2(b)) shows smooth surface morphology. However, the loading of $\mathrm{ZnO}$ into zeolite (Fig.-2(ce)) resulted in the coarse surface due to the formation of $\mathrm{ZnO}$ clusters on the surface of the zeolite. More $\mathrm{ZnO}$ clusters are formed upon increasing the $\mathrm{ZnO}$ loading. To find out how the distribution of $\mathrm{ZnO}$ in the sample, the SEM analysis is continued by mapping of Zn element using Energy Dispersive X-Ray Spectroscopy (EDS). The mapping images representing the distribution of $\mathrm{Zn}$ in the $\mathrm{ZnO}-\mathrm{NZ}$ are given in Fig.-3. The result showed that the distribution of dots representing $\mathrm{Zn}$ is getting denser with the increasing percentage of $\mathrm{ZnO}$ on $\mathrm{ZnO}-\mathrm{NZ}$. Also, the results also showed that $\mathrm{Zn}$ is well distributed on the $\mathrm{ZnO}-\mathrm{NZ}$ photocatalysts. This indicated that $\mathrm{ZnO}$ was well distributed in the zeolite frameworks.

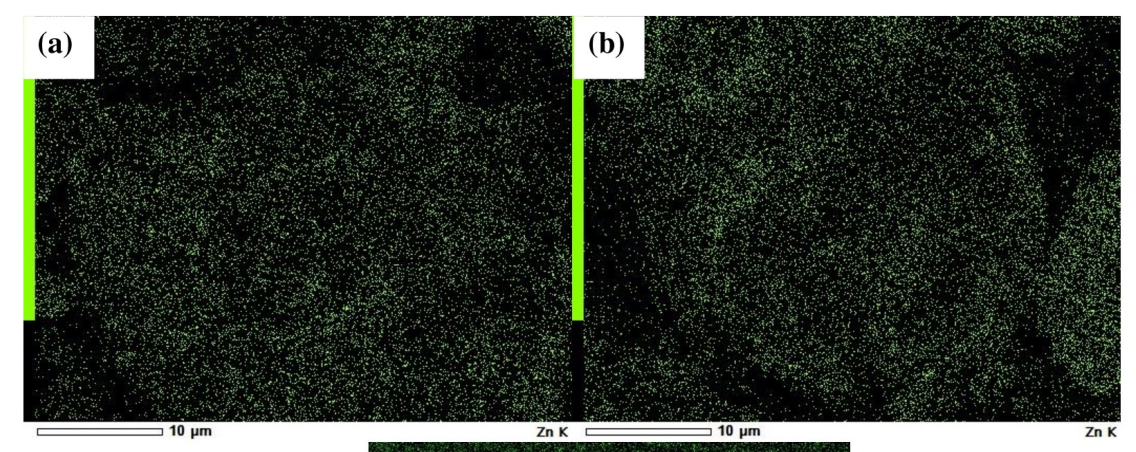

(c)

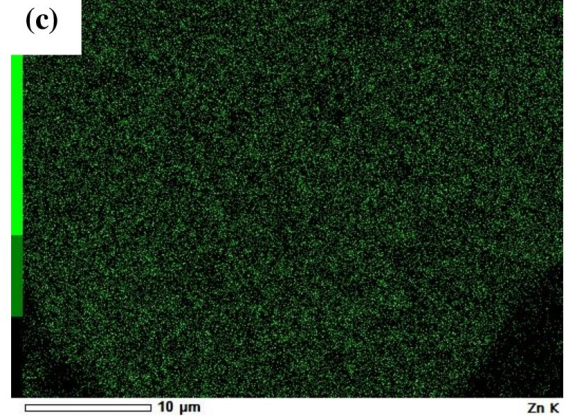

Fig.-3: EDX Mapping of $\mathrm{ZnO}$ in $\mathrm{ZnO}(3.5 \%)-\mathrm{NZ}$ (a), ZnO(5.0\%)-NZ (b) and $\mathrm{ZnO}(6.1 \%)-\mathrm{NZ}$ (c)

\section{Gas Sorption Analyzer}

The effect of the loading of $\mathrm{ZnO}$ into natural zeolite on their specific surface area, total pore volume, and average pore radius are presented in Table- 2 . The results show that the loading of $\mathrm{ZnO}$ into zeolites decreases the specific surface area $\left(\mathrm{S}_{\mathrm{BET}}\right)$ and total pore volume $(\mathrm{Vp})$ of the zeolites, as also observed by some researchers. ${ }^{18,26,27}$ The loading of $\mathrm{ZnO}$ into the pore of zeolite causes the narrowing and siltation of the pores. Thus, the surface area decreases.

Table-2:Pore Character of ZnO, Natural Zeolite (NZ), and ZnO-NZ based on the Adsorption-Desorption of $\mathrm{N}_{2}$ gas

\begin{tabular}{c|c|c|c}
\hline Samples & $\begin{array}{c}\text { Specific Surface Area, } \mathrm{S}_{\mathrm{BET}} \\
\left(\mathrm{m}^{2} / \mathrm{g}\right)\end{array}$ & $\begin{array}{c}\text { Total Pore Volume, } \mathrm{V}_{\mathrm{p}} \\
\left(\mathrm{cm}^{3} / \mathrm{g}\right) \times\left(10^{-2}\right)\end{array}$ & $\begin{array}{c}\text { Average Pore } \\
\text { Radius, } \mathrm{r}_{\mathrm{p}}(\AA)\end{array}$ \\
\hline $\mathrm{ZnO}$ & 24.300 & 20.71 & 154.80 \\
\hline $\mathrm{NZ}$ & 39.567 & 16.88 & 79.12 \\
\hline $\mathrm{ZnO}(3.5 \%)-\mathrm{NZ}$ & 34.459 & 14.79 & 80.40 \\
\hline $\mathrm{ZnO}(5.0 \%)-\mathrm{NZ}$ & 33.375 & 14.03 & 83.79 \\
\hline $\mathrm{ZnO}(6.1 \%)-\mathrm{NZ}$ & 31.835 & 13.17 & 84.10 \\
\hline
\end{tabular}

However, compared with bare $\mathrm{ZnO}$, the $\mathrm{ZnO}-\mathrm{NZ}$ provided a higher specific surface area. It seems the natural zeolite confines the growth of $\mathrm{ZnO}$ so that resulting $\mathrm{ZnO}$ with small particle size. The small size of $\mathrm{ZnO}$ increases the gap between the valence and the conduction band, as seen in Table-3. The 
RASĀYAN J. Chem.

Vol. 13 | No. 1 |747-756| January - March | 2020

decreasing of $\mathrm{ZnO}$ particle size increases the surface area of the photocatalyst and it gives advantages to the adsorption of pollutants on the photocatalyst surface.

\section{DRS UV-Vis}

The DRS UV-Vis spectra of the bare $\mathrm{ZnO}$ and $\mathrm{ZnO}-\mathrm{NZ}$ in the wavelength range of 200-800 $\mathrm{nm}$ are presented in Fig.-4. The absorption spectrum of the bare $\mathrm{ZnO}$ shows the strong and large broad absorption band in the UV region due to the $\mathrm{O}^{2-} \rightarrow \mathrm{Zn}^{2+}$ ligand to metal charge transfer transition. ${ }^{27,28}$ The UV-Vis DRS absorption spectra of $\mathrm{ZnO}-\mathrm{NZ}$ show similar absorption spectra to $\mathrm{ZnO}$ that have high absorption intensity in the UV region attributed to the $\mathrm{ZnO}$ particles embedded in the natural zeolite structure. The intensity of absorption in the UV region increases by rising of $\mathrm{ZnO}$ percentage in $\mathrm{ZnO}-\mathrm{NZ}$. This result is in good agreement with other research results. ${ }^{21}$

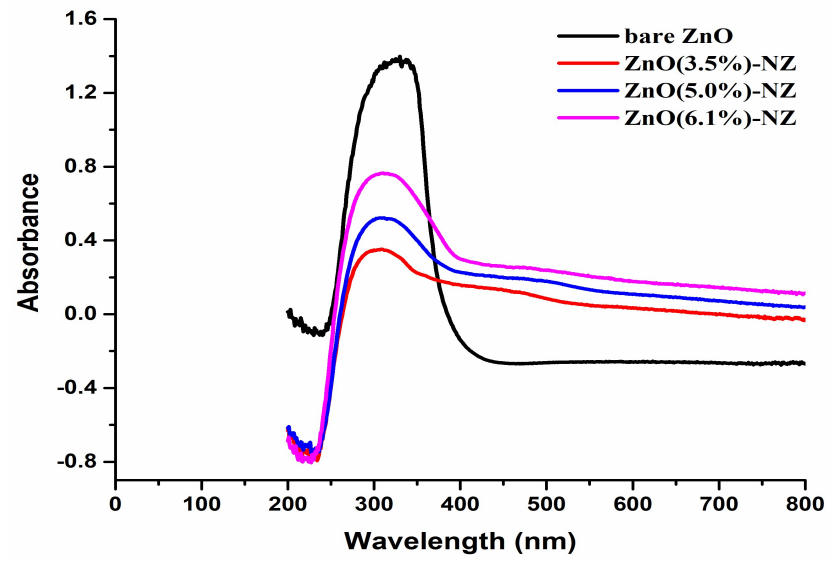

Fig.-4: The UV-Vis DRS Spectra of Bare $\mathrm{ZnO}$ and $\mathrm{ZnO}-\mathrm{NZ}$

The bandgap energy (Eg) can be determined based on the absorption edge wavelength $(\lambda)$ from DRS UV-Vis spectra data, employing the relationship of $E_{g}=1239 / \lambda .^{29}$ The absorption edge wavelength $(\lambda)$ and the bandgap energy $\left(\mathrm{E}_{\mathrm{g}}\right)$ of $\mathrm{ZnO}$ and $\mathrm{ZnO}-\mathrm{NZ}$ are shown in Table-3.

Table-3: Absorption Edge Wavelength $(\lambda)$ and the Bandgap Energy $\left(\mathrm{E}_{\mathrm{g}}\right)$ of Bare $\mathrm{ZnO}$ and ZnO-NZ.

\begin{tabular}{c|c|c}
\hline Samples & $\lambda(\mathrm{nm})$ & $\mathrm{E}_{\mathrm{g}}(\mathrm{eV})$ \\
\hline $\mathrm{Bare} \mathrm{ZnO}$ & 408 & 3.04 \\
\hline $\mathrm{ZnO}(3.5 \%)-\mathrm{NZ}$ & 371 & 3.34 \\
\hline $\mathrm{ZnO}(5.0 \%)-\mathrm{NZ}$ & 390 & 3.18 \\
\hline $\mathrm{ZnO}(6.1 \%)-\mathrm{NZ}$ & 399 & 3.11 \\
\hline
\end{tabular}

The results in Table- 3 confirm that the loading of $\mathrm{ZnO}$ into natural zeolite caused blueshifts in the edge wavelength. This blueshift indicates a decrease in $\mathrm{ZnO}$ particle size, as stated in the Bruss equation. ${ }^{30}$ The confinement effect due to reduced particle size narrows the bandwidth. This narrowing of the bandwidth causes the distance or the gap between the valence band and the conduction band to increase so that the bandgap energy becomes higher.

The largest blueshift is at $\mathrm{ZnO}(3.5 \%)-\mathrm{NZ}$ which is shifted from $408 \mathrm{~nm}$ for the bare $\mathrm{ZnO}$ to $371 \mathrm{~nm}$ for $\mathrm{ZnO}(3.5 \%)-\mathrm{NZ}$. Those resulted in the bandgap energy of 3.04 and $3.34 \mathrm{eV}$, respectively. Increasing the amount of $\mathrm{ZnO}$ in the zeolite of $5-6 \%$ produces smaller bandgap energy than $3.34 \mathrm{eV}$ indicating the formation of the larger size of $\mathrm{ZnO}$ particles. At high $\mathrm{ZnO}$ concentrations of higher than 3.5\%, $\mathrm{ZnO}$ tends to aggregate to form large $\mathrm{ZnO}$ particles. However, in this study, the size of $\mathrm{ZnO}$ in $\mathrm{ZnO}-\mathrm{NZ}$ is still smaller than the bare $\mathrm{ZnO}$.

\section{Photocatalytic Activity Examination}

To evaluate the effect of zeolite as supporting material on the photocatalytic activity of $\mathrm{ZnO}-\mathrm{NZ}$ for $\mathrm{MB}$ photodegradation, several experiments have been done, namely without using photocatalyst, using the 
RASĀYAN J. Chem.

Vol. 13 | No. 1 |747-756| January - March | 2020

bare $\mathrm{ZnO}$, and $\mathrm{ZnO}-\mathrm{NZ}$ at the same conditions. The results of the degradation at various irradiation times are presented in Fig. -5 .

The un-photocatalyzed degradation of MB under UV light irradiation is found to take place with low efficiency. The degradation of MB in the presence of UV light could be caused by the distortion of the chromophore groups in the dye by the high energy of UV. The chromophores may undergo photodecomposition through the formation of radical species. ${ }^{31}$ The degradation caused by attacking by hydroxyl radicals $(\cdot \mathrm{OH})$ resulted from $\mathrm{H}_{2} \mathrm{O}$ photolysis is also possible. ${ }^{32}$ The effect of $\mathrm{UV}$ light and water photolysis is implied to be weaker, which is indicated by the low efficiency of the degradation.

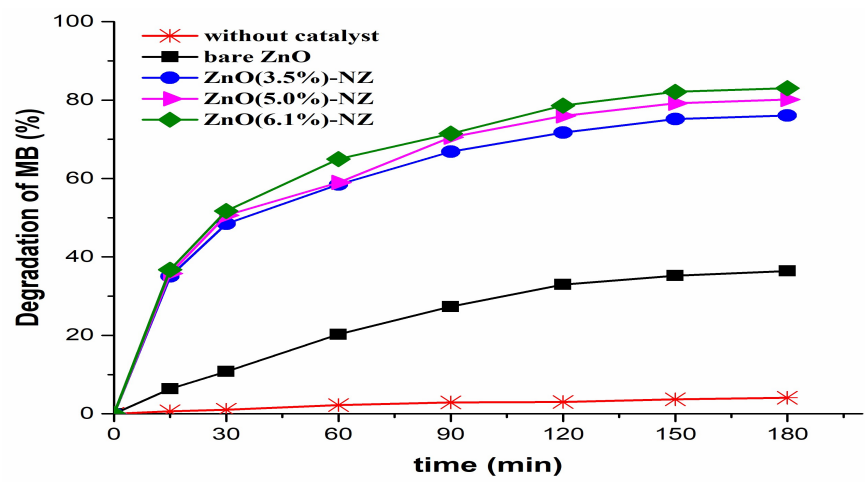

Fig.-5: Photocatalytic degradation of MB under UV light

The increasing effectiveness of the $\mathrm{MB}$ over $\mathrm{ZnO}$ is also observed in Fig.-5. Degradation of $\mathrm{MB}$ can occur due to the attack of $\cdot \mathrm{OH}$ radicals generated by $\mathrm{ZnO}$ during $\mathrm{UV}$ irradiation. The reactions are presented as equation (2-4) below: ${ }^{12,33}$

$$
\begin{aligned}
& \mathrm{ZnO}+h v \rightarrow \mathrm{ZnO}\left(h_{V B}^{+}+e_{C B}^{-}\right) \\
& h_{V B}^{+}+\mathrm{OH}^{-} \rightarrow \mathrm{gOH} \\
& \mathrm{gOH}+\text { dyes } \rightarrow \text { intermediate } \rightarrow \text { final products }
\end{aligned}
$$

In this stage, the $\cdot \mathrm{OH}$ radicals provided by $\mathrm{ZnO}$ photocatalyst is much more compared to that by water photolysis. This explains the more effective degradation of $\mathrm{MB}$ over $\mathrm{ZnO}$ by the presence of $\mathrm{UV}$ light. Moreover, $\mathrm{ZnO}-\mathrm{NZ}$ showed higher activity because $\mathrm{ZnO}$ supported on the zeolite structure has a smaller particle size, providing the larger surface area. The larger surface area gives more effective contact between $\mathrm{MB}$ and the $\cdot \mathrm{OH}$ radicals formed on the surface of the photocatalyst ${ }^{15,19}$, resulting in higher photodegradation. The high photodegradation activity of $\mathrm{ZnO}-\mathrm{NZ}$ may be also promoted by effective $\mathrm{MB}$ adsorption on zeolite. The increasing of the specific surface area of the photocatalyst after supported into zeolite provided higher adsorption capacity of MB. Also, the high adsorption capacity of ZnO-NZ for the $\mathrm{MB}$ cationic dye is also due to the electronegativity properties of zeolites. This high adsorption capacity of $\mathrm{ZnO}-\mathrm{NZ}$ is advantageous to the photocatalysis process because it brings more MB molecules near the $\mathrm{ZnO}$ surface. ${ }^{19}$ Zeolites may facilitate the photoactive species $\left(h^{+}{ }_{\mathrm{VB}}\right.$ and $\left.e_{\mathrm{CB}}^{-}\right)$from the $\mathrm{ZnO}$ surface to $\mathrm{MB}$ molecule that adsorbed in zeolites and vice versa from zeolite to the $\mathrm{ZnO}$ surface. This situation promotes more degradation of the MB. ${ }^{18}$

When $\mathrm{ZnO}$ supported into zeolite, they form the $\mathrm{Zn}-\mathrm{O}-\mathrm{Si}$ or $\mathrm{Zn}-\mathrm{O}-\mathrm{Al}$ as shown by the FTIR spectra (Fig.1(b)). As the characteristics of zeolite, $\mathrm{ZnO}-\mathrm{NZ}$ has high thermal and chemical stability that prevents the $\mathrm{ZnO}$ to experience corrosion that may reduce the activity of photocatalysts. When $\mathrm{ZnO}-\mathrm{NZ}$ is exposed to $\mathrm{UV}$ light, the electron of $\mathrm{ZnO}$ is excited from the valence band to conductance band $\left(e_{\mathrm{CB}}^{-}\right)$and leaving a hole behind $\left(h_{\mathrm{VB}}^{+}\right)$. The excited electrons in zinc cations migrate to oxygen atoms and finally to $\mathrm{Al}$ atoms. ${ }^{18,19}$ This prevents the recombination of electrons and holes during photoreaction ${ }^{18,19}$, thereby increasing the chance of the hole reacts with the hydroxide to produce hydroxyl radicals that plays an important role in the degradation process. ${ }^{12,34}$ The increasing bandgap of $\mathrm{ZnO}$ supported into zeolite also 


\section{RASĀYAN J. Chem.}

Vol. 13 | No. 1 |747 - 756| January - March | 2020

increases the separation between the electrons in the conduction band $\left(e_{\mathrm{CB}}^{-}\right)$and the hole in the valence band $\left(h^{+}{ }_{\mathrm{VB}}\right)$, so the possibility of its recombination is getting smaller and obtain a high photocatalytic activity.

In this study, although the specific surface area of $\mathrm{ZnO}-\mathrm{NZ}$ slightly decreases with the increase of $\mathrm{ZnO}$ percentage from $3.5 \%$ to $6.0 \%$ in the $\mathrm{ZnO}-\mathrm{NZ}$, the photocatalytic activities slightly increase. This due to the higher of $\mathrm{ZnO}$ amount in photocatalyst, the more radical produce so that the more MB may degrade. The photodegradation percentage of $\mathrm{ZnO}(3.5 \%)-\mathrm{NZ}, \mathrm{ZnO}(5.0 \%)-\mathrm{NZ}$, and $\mathrm{ZnO}(6.0 \%)-\mathrm{NZ}$ are $76.10 \%$, $80.13 \%$ and $83.05 \%$ respectively.

The effect of the dosage of photocatalyst on MB degradation efficiency is displayed by Fig.-6(a). The result showed that the degradation percentage of MB increases by the increase in photocatalyst dosage. This trend occurs since more amount of photocatalyst, more $\cdot \mathrm{OH}$ radicals are provided, resulting in more effective degradation. However, at too high photocatalyst dosage, the increasing turbidity of solution causes the photon penetration to the solution reduces, thereby the photocatalyst becomes less active. As a result, at higher photocatalyst dosage is less effective to increase the degradation percentage.
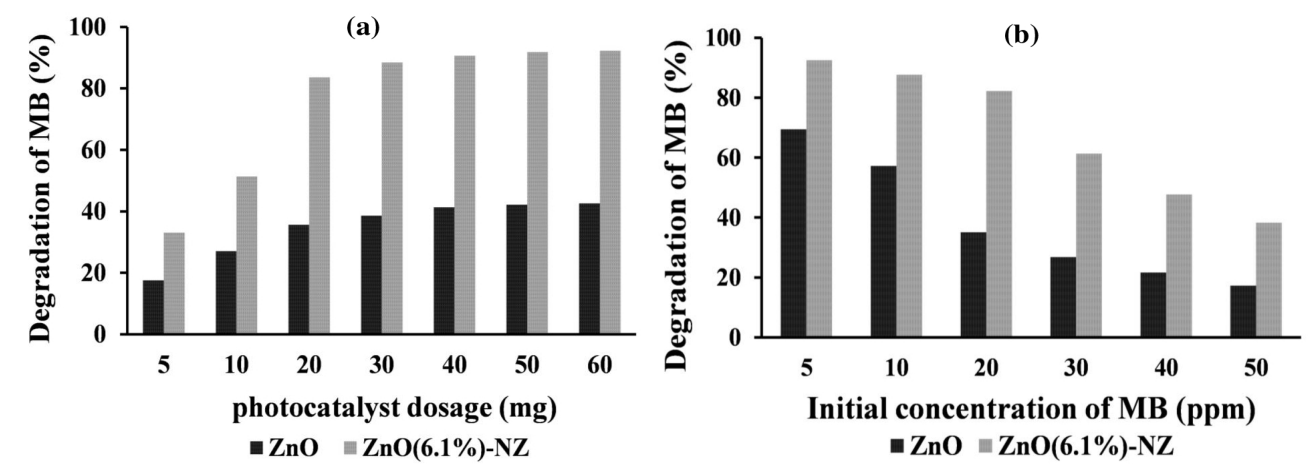

Fig.-6: Effect of the Photocatalyst Dosage (a) and the Initial Concentration of MB (b) On Photocatalytic Activity of $\mathrm{ZnO}$ and $\mathrm{ZnO}(6.1 \%)-\mathrm{NZ}$ under UV Light

To determine the effect of the initial MB concentration on the effectivity of photocatalyst, some experiments were carried out using 5-50 ppm of MB. The results in Fig.-6(b) showed that the degradation percentage of MB decreases with increasing the initial concentration of MB. This decrease due to the hydroxyl radicals that are produced remains constant, whereas the amount of MB molecules increases by increasing $\mathrm{MB}$ concentration. Also, at higher $\mathrm{MB}$ concentration, too many $\mathrm{MB}$ adsorbed in the photocatalyst surface causes the blocking of the light penetration to the surface of photocatalyst thereby reducing its activity.

\section{CONCLUSION}

Supported $\mathrm{ZnO}$ into natural zeolite ( $\mathrm{ZnO}-\mathrm{NZ}$ ) has been successfully prepared by cation exchange followed by co-precipitation and calcination process. ZnO-NZ has a higher specific surface area and a wide bandgap. Methylene blue as a persistent organic pollutant was successfully photodegraded by $\mathrm{ZnO}$ NZ under the irradiation of UV light. Supported $\mathrm{ZnO}$ into natural zeolite increases the activity of the photocatalyst more than twice compared to the bare $\mathrm{ZnO}$. The highest degradation percentage of $83.05 \%$ was obtained at $\mathrm{ZnO}(6.1 \%)-\mathrm{NZ}$.

\section{ACKNOWLEDGMENT}

The authors are grateful to the Directorate General of Higher Education, Indonesian Ministry of Research, Technology and Higher Education for funding this research and the University of Gadjah Mada for providing the research facilities.

\section{REFERENCES}

1. M. Rafatullah, O. Sulaiman, R. Hashim and A. Ahmad, Journal of Hazardous Materials, 177, 70 (2010), DOI:10.1016/j.jhazmat.2009.12.047

2. T. Liu, Y. Li, Q. Du, J. Sun, Y. Jiao, G. Yang, Z. Wang, Y. Xia, W. Zhang, K. Wang, H. Zhu and D. Wu, Colloids and Surface B: Biointerfaces, 90, 197 (2012), DOI:10.1016/j.colsurfb.2011.10.019 
RASĀYAN J. Chem.

Vol. 13 | No. 1 |747 - 756| January - March | 2020

3. S.K. Theydan and M.J. Ahmed, Journal of Analytical Applied Pyrolysis, 97, 116(2012), DOI:10.1016/j.jaap.2012.05.008

4. Z. Carmen and S. Daniela, 2012, Textile Organic Dyes - Characteristics, Polluting Effects and Separation/Elimination Procedures from Industrial Effluents - A Critical Overview, in T. Puzyn and A. Mostrag-Szlichtyng (Eds.), Organic Pollutants Ten Years After the Stockholm Convention Environmental and Analytical Update, InTech, Croatia, pp.55-86, DOI:10.5772/32373

5. C. Djelloul and O. Hamdaoui, Desalination and Water Treatment, 52(40-42), 7701(2014), DOI: $10.1080 / 19443994.2013 .833555$

6. V. Bharti, K. Vikrant, M. Goswami, H. Tiwari, R.K. Sonwani, J. Lee, D.C.W. Tsang, K.H. Kim, M. Saeed, S. Kumar, B.N. Rai, B.S. Giri and R.S. Singh, Environmental Research, 171, 356 (2019), DOI: 10.1016/j.envres.2019.01.051

7. O.F. Sarioglu, N.O.S. Keskin, A. Celebioglu, T. Tekinay and T. Uyar, Colloids and Surface B: Biointerfaces, 152, 245(2017), DOI:10.1016/j.colsurfb.2017.01.034

8. N. Saibaba KV and R.V. Kandisa, Rasāyan Journal of Chemistry, 12(4), 2176(2019), DOI: $10.31788 /$ RJC.2019.1245478

9. Y.A.B. Neolaka, E.B.S. Kalla, G.A. Malelak, N.K. Rukman, G. Supriyanto and N.N.T. Puspaningsih, Rasāyan Journal of Chemistry, 11(2), 494(2018), DOI:10.31788/RJC.2018.1121994

10. J. Gandhi, R. Dangi and S. Bhardwaj, Rasāyan Journal of Chemistry, 1(3), 567(2008)

11. N.P. Mohabansi, V.B. Patil and N. Yenkie, Rasāyan Journal of Chemistry, 4(4), 814(2011).

12. K.M. Lee, C.W. Lai, K.S. Ngai and J.C. Juan, Water Research, 88, 428(2016), DOI:10.1016/j.watres.2015.09.045

13. C.B. Ong, L.Y. Ng and A.W. Mohammad, Renewable and Sustainable Energy Reviews, 81, 536 (2018), DOI: 10.1016/j.rser.2017.08.020

14. Y. Liu, S. Wei and W. Gao, Journal of Hazardous Materials, 287, 59 (2015), DOI:10.1016/j.jhazmat.2014.12.045

15. A. Nezamzadeh-Ejhieh and S. Khorsandi, Journal of Industrial and Engineering Chemistry, 20, 937 (2014), DOI: 10.1016/j.jiec.2013.06.026

16. T.T. Vu, L. del Río, T. Valdés-Solís and G. Marbán, Applied Catalysis B: Environmental, 140-141, 189 (2013), DOI: $10.1016 /$ j.apcatb.2013.04.023

17. Y. Zhang, Z. Chen, S. Liu and Y.J. Xu, Applied Catalysis B: Environmental, 140-141, 598 (2013), DOI:10.1016/j.apcatb.2013.04.059

18. A. Nezamzadeh-Ejhieh and F. Khodabakshi-Chermahini, Journal of Industrial and Engineering Chemistry, 20(2), 695 (2014), DOI:10.1016/j.jiec.2013.05.035

19. M. Bahrami and A. Nezamzadeh-Ejhieh, Materials Science in Semiconductor Processing, 30, 275(2015), DOI:10.1016/j.mssp.2014.10.006

20. T. Gong, L. Qin, J. Lu and H. Feng, Physical Chemistry Chemical Physics, 18, 601(2016), DOI:10.1039/C5CP05043J

21. J. Chen, Z. Feng, P. Ying and C. Li, Journal of Physical Chemistry B, 108, 12669(2004), DOI:10.1021/jp048746x

22. B.J. Saikia and G. Parthasarathy, Journal of Modern Physics, 1(4), 206(2010), DOI:10.4236/jmp.2010.14031

23. Z. Liu, Z. Liu, T. Cui, J. Li, J. Zhang, T. Chen, X. Wang and X. Liang, Chemical Engineering Journal, 235, 257(2014), DOI:10.1016/j.cej.2013.09.022

24. K. Byrappa and B.V.S. Kumar, Asian Journal of Chemistry, 2007, 19(6), 4933(2007).

25. E.P. Favvas, C.G. Tsanaktsidis, A.A. Sapalidis, G.T. Tzilantonis, S.K. Papageorgiou and A.C. Mitropoulos, Microporous and Mesoporous Materials, 225, 385 (2016), DOI:10.1016/j.micromeso.2016.01.021

26. B. Lin, J. Wang, Q. Huang, M. Ali and Y. Chi, Journal of Analytical and Applied Pyrolysis, 128, 291 (2017), DOI: 10.1016/j.jaap.2017.09.021

27. O. Sacco, V. Vaiano and M. Matarangolo, Separation and Purification Technology, 193, 303 (2018), DOI:10.1016/j.seppur.2017.10.056 
RASĀYAN J. Chem.

Vol. 13 | No. 1 |747 - 756| January - March | 2020

28. L. Wang, S. Sang, S. Meng, Y. Zhang, Y. Qi and Z. Liu, Materials Letters, 61, 1675(2007), DOI:10.1016/j.matlet.2006.07.097

29. E.T. Wahyuni and R. Roto, 2018, Silver Nanoparticle Incorporated Titanium Oxide for Bacterial Inactivation and Dye Degradation, in D. Yang (Eds.), Titanium Dioxide: Material for a Sustainable Environment, Intechopen, pp. 331-348, DOI:10.5772/intechopen.70290

30. E.O. Chukwuocha, M.C. Onyeaju and T.S.T. Harry, World Journal of Condensed Matter Physics, 2, 96 (2012), DOI:10.4236/wjcmp.2012.22017

31. J. Albaigés, J.M. Bayona and J.R. Radović, 2016, Photochemical effect on oil spill fingerprinting, in S.A. Stout and Z. Wang, Standard Handbook in Oil Spill Environmental Forensics, $2^{\text {nd }}$ edition, Academic Press, New York, pp. 917-959, DOI:10.1016/B978-0-12-803832-1.00020-9

32. J.L. Wang and L.J. Xu, Critical Reviews in Environmental Science Technology, 42, 251(2012), DOI:10.1080/10643389.2010.507698

33. R.E. Adam, G. Pozina, M. Willander and O. Nur, Photonics and Nanostructures - Fundamentals and Applications, 32, 11(2018), DOI:10.1016/j.photonics.2018.08.005

34. K. Akhil, J. Jayakumar, G. Gayathri and S.S. Khan, Journal of Photochemistry \&. Photobiology, B: Biology, 160, 32(2016), DOI:10.1016/j.jphotobiol.2016.03.015

[RJC-5597/2019] 